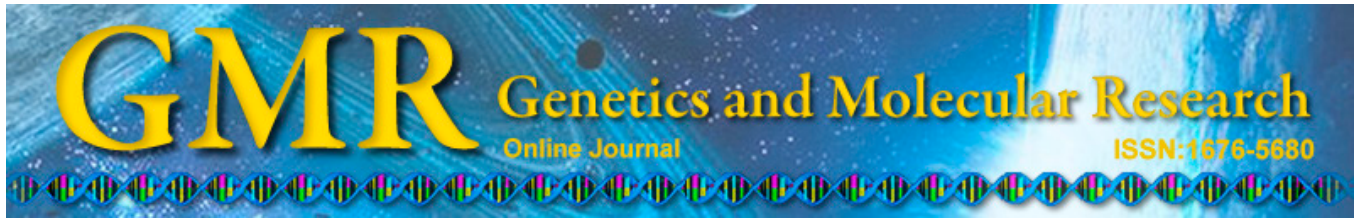

\title{
LAMP-PCR detection of ochratoxigenic Aspergillus species collected from peanut kernel
}

\author{
H.M. Al-Sheikh \\ Saudi Arabia \\ Corresponding author: H.M. Al-Sheikh \\ E-mail: Plxha@kfu.edu.sa \\ Genet. Mol. Res. 14 (1): 634-644 (2015) \\ Received April 11, 2014 \\ Accepted November 4, 2014 \\ Published January 30, 2015 \\ DOI http://dx.doi.org/10.4238/2015.January.30.5
}

Department of Biology, College of Science, King Faisal University, AlHassa,

\begin{abstract}
Over the last decade, ochratoxin A (OTA) has been widely described and is ubiquitous in several agricultural products. Ochratoxins represent the second-most important mycotoxin group after aflatoxins. A total of 34 samples were surveyed from 3 locations, including Mecca, Madina, and Riyadh, Saudi Arabia, during 2012. Fungal contamination frequency was determined for surfacesterilized peanut seeds, which were seeded onto malt extract agar media. Aspergillus niger (35\%), Aspergillus ochraceus (30\%), and Aspergillus carbonarius (25\%) were the most frequently observed Aspergillius species, while Aspergillus flavus and Aspergillus phoenicis isolates were only infrequently recovered and in small numbers $(10 \%)$. OTA production was evaluated on yeast extract sucrose medium, which revealed that $57 \%$ of the isolates were $A$. niger and $60 \%$ of $A$. carbonarius isolates were OTA producers; $100 \%$ belonged to $A$. ochraceus. Only one isolate, morphologically identified as $A$. carbonarius, and 3 A. niger isolates unstably produced OTA. A polymerase chain reaction (PCR)-based identification and detection assay was used to identify $A$. ochraceus isolates. Using the primer sets OCRA1/OCRA2, 400-base pair PCR fragments were produced only when genomic DNA from $A$. ochraceus isolates was used. Recently, the loop-mediated isothermal amplification assay using recombinase polymerase amplification chemistry was used for A. carbonarius
\end{abstract}


and $A$. niger DNA identification. As a non-gel-based technique, the amplification product was directly visualized in the reaction tube after adding calcein for naked-eye examination.

Key words: Arachis hypogaea; Black aspergilla; Ochratoxins; Loop-mediated isothermal amplification; Polymerase chain reaction

\section{INTRODUCTION}

Black aspergilla, including Aspergillus carbonarius, Aspergillus awamori, and Aspergillus niger, have been reported to be the main producers of ochratoxin A (OTA) (Abarca et al., 2004). Aspergillus ochraceus can infest many agricultural commodities, including cereals, coffee, peanuts, grapes, and others, often producing numerous mycotoxins such as OTA, viomellein, and penicillic acid. A. carbonarius is considered to be responsible for OTA contamination in grapes, wines, and coffee (Battilani et al., 2006). Other nonochratoxigenic black aspergilli collected from grapes in European vineyards are typically found to belong to the species Aspergillus tubingensis and Aspergillus uvarum (Perrone et al., 2007; Varga et al., 2011). OTA is a nephropatic, teratogenic, and carcinogenic mycotoxin found in food commodities and produced by some food-borne Aspergillus species (Belli et al., 2004). The Aspergillus species section Nigri are difficult to identify and classify; however, some taxonomic systems have been suggested. Aspergillius species identification based on cultural, morphological, and biochemical characters is laborious and not always straight forward. Molecular markers are useful for these studies (Geiser et al., 2007). Molecular methods have decreased the number of synonym names of defined species within the black aspergilli and supported the division of this "aggregate" in 2-4 morphologically undetectable species: A. niger, A. tubingensis, Aspergillus foetidus, and Aspergillus brasiliensis (Abarca et al., 2004). These 4 species are very difficult to distinguish using 23 cultural and morphological criteria, such as conidial shape, color, and size (Samson et al., 2004). Recently, some polymerase chain reaction (PCR)- and real-time PCRbased assays have been established for the fast and specific identification of aspergilla collected from agricultural commodities (Selma et al., 2008; Sardiñas et al., 2010). As an alternative to PCR-based analysis, loop-mediated isothermal amplification (LAMP) (Notomi et al., 2000) is an easy and rapid analytical tool for the early detection of toxigenic fungi (Niessen and Vogel, 2010). In addition, LAMP was developed for the fast detection of pathogenic or allergenic fungi in the environment (Sun et al., 2010). Recently, LAMP-PCR methods using internal labeled probes have been developed for the important Fusarium head blight pathogens in materials of different plants (Niessen and Vogel, 2010; Abd-Elsalam et al., 2011; Niessen et al., 2012). These methods have been used to detect plant pathogenic fungi such as Phytophthora ramorum (Tomlinson et al., 2007), Phytophthora sojae (Dai et al., 2012), toxigenic Fusarium (Denschlag et al., 2012; Niessen et al., 2012; Almoammar et al., 2013), Aspergillus flavus and Aspergillus parasiticus (Ahmad et al., 2010), A. flavus, A. parasiticus, Aspergillus nomius, and Aspergillus caelatus (Luo et al., 2012, 2014), and A. carbonarius and A. niger (Storari et al., 2013). Based on the data presented in the literature, the LAMP-based assay may constitute a potentially valuable molecular tool for the rapid diagnosis of ochratoxigenic Aspergillus species in agricultural products. The aims of this study were to identify dominant ochratoxigenic Aspergillus species in peanuts collected from Saudi Arabia and to evaluate specific PCR and LAMP-PCR assays for identifying and quantifying OTA-producing aspergilli collected from peanuts. 


\section{MATERIAL AND METHODS}

\section{Peanut samples and fungal isolation}

Thirty-four samples of peanut kernels were obtained arbitrarily from different supermarkets in 3 locations, including Mecca, Madina, and Riyadh, Saudi Arabia during 2012. Samples were stored at $4^{\circ} \mathrm{C}$ until fungal enumeration. Peanut kernels were used either after surface sterilization using $2 \%$ sodium hypochlorite solution or after being washed 3 times with sterile distilled water for $3 \mathrm{~min}$. Five peanut kernels were randomly divided and directly seeded on Petri dishes containing malt extract agar in triplicate. Petri dishes were incubated at 25 $\pm 2^{\circ} \mathrm{C}$ and the emerging colonies were counted after 5 days. Fungal colonies were purified and then identified morphologically and microscopically according to Pitt and Hocking (1997). All isolates were maintained as slant cultures using potato dextrose agar medium at $4^{\circ} \mathrm{C}$.

\section{Ochratoxigenic ability of the isolates}

Collected isolates were tested for OTA production following the method described by Téren et al. (1996) with some modifications: the isolates were grown in stationary cultures in $25-\mathrm{mL}$ quantities of YES medium ( $2 \%$ yeast extract, $15 \%$ sucrose) at $28^{\circ} \mathrm{C}$ for 10 days in the dark. After incubation, $1 \mathrm{~mL}$ culture media was mixed with $1 \mathrm{~mL}$ chloroform and centrifuged at $4000 \mathrm{~g}$ for $10 \mathrm{~min}$. The chloroform fraction was transferred to a clean tube, evaporated to dryness, and redissolved in $0.5 \mathrm{~mL}$ methanol. Next, OTA was detected according to the previously described procedures.

A high-performance liquid chromatography system (Shimadzu; Kyoto, Japan) was used with the fluorescence detection set at $333 \mathrm{~nm}$ for excitation and $477 \mathrm{~nm}$ for emission. The mobile phase consisted of acetonitrile:water:acetic acid $(51: 47: 2, \mathrm{v} / \mathrm{v} / \mathrm{v})$ and the flow rate was $1 \mathrm{~mL} / \mathrm{min}$. An OTA stock was used to prepare 5 standard curves of peak areas versus concentration $(\mu \mathrm{g} / \mathrm{L})$. The OTA standard was purchased from Sigma (Ref.O-1877; St. Louis, MO, USA). Samples with an OTA level below $1 \mu \mathrm{g} / \mathrm{kg}$ were considered to be negative controls.

\section{Fungal isolates and DNA extraction}

Aspergillius species isolates used in this study are listed in Table 1. Total genomic DNA was purified from fresh mycelia of Aspergillus isolates were extracted using a modified method (Bahkali et al., 2012).

\section{Specific PCR assay}

PCR amplification was carried out using 2 sets of primers: OCRA1/OCRA2 (5'-CTTCCTTAGGGGTGGCACAGC-3' and 5'-GTTGCTTTTCAGCGTCGGCC-3', respectively) for $A$. ochraceus (Patiño et al., 2005). For the PCR, $1 \mu \mathrm{L}$ DNA sample solution was mixed with $24 \mu \mathrm{L}$ PCR stock solution containing $2.5 \mu \mathrm{L}$ 10X PCR buffer (Qiagen; Hilden, Germany), $2 \mu \mathrm{L} 25 \mathrm{mM} \mathrm{MgCl}, 0.5 \mu \mathrm{L} 10 \mathrm{mM}$ dNTP mixture, $1 \mu \mathrm{L}$ of each primer (20 pmol), $0.2 \mu \mathrm{L} 5 \mathrm{U} / \mu \mathrm{L}$ Taq polymerase (Qiagen), and $16.3 \mu \mathrm{L}$ sterile deionized $\mathrm{H}_{2} \mathrm{O}$. The amplification thermal parameters were: $4 \mathrm{~min}$ at $95^{\circ} \mathrm{C}$, followed by 40 amplification cycles at $95^{\circ} \mathrm{C}$ for $30 \mathrm{~s}$, $55^{\circ} \mathrm{C}$ for $30 \mathrm{~s}$, and $72^{\circ} \mathrm{C}$ for $20 \mathrm{~s}$. PCR products were analyzed by electrophoresis on a $1.5 \%$ 
agarose gel in TAE buffer. Ethidium bromide-stained gels $(0.5 \mu \mathrm{g} / \mathrm{mL}$ gel $)$ were visualized under ultraviolet light and photographed using a gel-doc system (Bio-Rad Laboratories; Hercules, CA, USA).

Table 1. Ochratoxin A (OTA) production capabilities of Aspergillus isolates used in this study and PCR amplification products with the primer pair OCRA1/OCRA2. The 2 LAMP primer sets (AnPKS and AcPKS) were used to detect $A$. niger and $A$. carbonarius, respectively.

\begin{tabular}{|c|c|c|c|c|}
\hline \multirow[t]{2}{*}{ Aspergillius species } & \multirow[t]{2}{*}{ OTA quantity $(\mu \mathrm{g} / \mathrm{g})$} & \multirow{2}{*}{$\frac{\text { PCR assay }}{\text { OCRA1/OCRA2 }}$} & \multicolumn{2}{|c|}{ LAMP-PCR } \\
\hline & & & AnPKS & AcPKS \\
\hline A. niger & 0.00 & $\square$ & . & $\square$ \\
\hline A. niger & 1.27 & $\square$ & - & $\square$ \\
\hline A. niger & 0.97 & $\square$ & a & $\square$ \\
\hline A. niger & 0.00 & $\square$ & - & $\square$ \\
\hline A. niger & 1.90 & $\square$ & 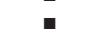 & $\square$ \\
\hline A. niger & 0.00 & $\square$ & ! & $\square$ \\
\hline A. niger & 0.00 & $\square$ & . & $\square$ \\
\hline A. ochraceus & 0.88 & - & $\square$ & $\square$ \\
\hline A. ochraceus & 0.36 & घ & $\square$ & $\square$ \\
\hline A. ochraceus & 0.79 & ! & $\square$ & $\square$ \\
\hline A. ochraceus & 1.18 & - & $\square$ & $\square$ \\
\hline A. ochraceus & 0.93 & घ & $\square$ & $\square$ \\
\hline A. ochraceus & 1.14 & 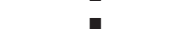 & $\square$ & $\square$ \\
\hline A. carbonarius & 0.00 & $\square$ & $\square$ & ! \\
\hline A. carbonarius & 1.63 & $\square$ & $\square$ & ! \\
\hline A. carbonarius & 0.23 & $\square$ & $\square$ & ! \\
\hline A. carbonarius & 1.45 & $\square$ & $\square$ & - \\
\hline A. carbonarius & 0.00 & $\square$ & $\square$ & 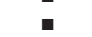 \\
\hline A. phoenicis & 0.00 & $\square$ & $\square$ & $\square$ \\
\hline A. flavus & 0.00 & $\square$ & $\square$ & $\square$ \\
\hline
\end{tabular}

The presence or absence of species-specific amplicon is indicated by a filled or open square, respectively, for each set of primers.

\section{LAMP reaction}

We used primer sets designed by Storari et al. (2013) with the nucleic acid sequences as shown in Table 2. The LAMP-PCR assay was carried out in a total of $25 \mu \mathrm{L}$ reaction mixture containing $2.5 \mathrm{mM}$ 10X Bst-DNA polymerase buffer, $10 \mu \mathrm{M}$ betaine, $2.5 \mathrm{mM}$ dNTPs, $10 \mathrm{mM}$ $\mathrm{MgSO}_{4}, 1.6 \mathrm{mM}$ of each forward inner primer and backward inner primer, $0.2 \mathrm{mM}$ of each $\mathrm{F} 3$ and $\mathrm{B} 3$ primers, $0.8 \mathrm{mM}$ of each loop-F and loop-B, $8 \mathrm{U}$ Bst-DNA polymerase (New England BioLabs; Ipswich, MA, USA), $\mathrm{ddH}_{2} \mathrm{O}$, and $1 \mu \mathrm{L}$ template DNA. Before incubation, $25 \mu \mathrm{M}$ calcein and $0.5 \mathrm{mM} \mathrm{MnCl}_{2}$ were added to each $25 \mu \mathrm{L}$ reaction mix. Sterile distilled $\mathrm{H}_{2} \mathrm{O}$ was used as a negative control template for all reactions. LAMP reactions were carried out at $63^{\circ} \mathrm{C}$ for $60 \mathrm{~min}$ using a thermal cycler (icycler; Bio-Rad). Visual inspection of the LAMP amplicons in the reaction tube were performed by adding fluorescent detection reagent before the incubation of the reaction tubes, the fluorescent signals of the solutions were detected under ultraviolet light. Direct visualization of the amplified product was achieved by electrophoresis of the LAMP reactions on $1.5 \%$ agarose gels following incubation. Gels were run at $60 \mathrm{~V}$ and $55 \mathrm{~mA}$ for $45 \mathrm{~min}$ and stained with $0.5 \mu \mathrm{g} / \mathrm{mL}$ ethidium bromide solution. The region amplified by the LAMP primers used here spanned 150 base pairs (bp). This was confirmed by the size of the smallest-sized band obtained after agarose gel electrophoresis of the LAMP reaction products. A DNA molecular weight marker of a 100-bp DNA ladder was used to determine the size of the LAMP products. 
Table 2. Loop-mediated isothermal amplification primers for the detection of Aspergillus carbonarius (AcPKS) and Aspergillus niger (AnPKS) used in the present study (Storari et al., 2013).

\begin{tabular}{lll}
\hline Primer sets & Primers sequence (5'-3') & Aspergillius species \\
\hline AcPKS FIP & GCTGCAATGCACCCGGTAG & \\
BIP & TTGAAGACGTGGius \\
& AAGTCACGTCAAAAGCCTTCT & \\
Loop F & TGATTCCTTGGGAGGTTGGTC & \\
Loop B & GCTGGCCGAAAAGATCGCTAA & \\
F3 & CCCCTCTGCTATGAAGTCCG & \\
B3 & TGGTGGTACGAATGCACAC & \\
AnPKS FIP & CGAAATGACAAACAGGCGGT & \\
& CCTGCGCCACCTTCCAAGTGC \\
BIP & GATTCGCCCCTCTATGTTG & \\
& CTGATCTCAGCCACACTGGCT & \\
Loop F & GATCTTGGGGTTCAAGCTCTG & \\
Loop B & CCAGCACGGATTTTACCGATC & \\
B3 & TAGAGTCGAAGATGATA CCCCCAGT & \\
\hline
\end{tabular}

All nucleotides were purchased from Eurofins MWG Operon (Ebersberg, Germany).

\section{RESULTS}

\section{Cultural and morphological characteristics}

Fungal colonies of $A$. carbonarius and $A$. niger on malt extract agar at $27^{\circ} \mathrm{C}$ were first white, and rapidly became black with conidial production. The inverse was pale yellow, and growth generated radial fissures on the agar. Malt extract agar allowed for faster growth and colonies appeared after 2-4 days. A. carbonarius and A. niger colonies were not distinguishable by eye (Figure 1).

Hyphae are composed of septate and hyaline. Conidial heads radiate initially, splitting into columns at maturity. The species is biseriate, which means that vesicles produce sterile cells known as metulae that support the conidiogenous phialides. Conidiophores are long (400-3000 $\mu \mathrm{m})$, smooth, and hyaline, and become darker at the apex, terminating in a globose vesicle (30-75 $\mu \mathrm{m}$ in diameter) (Figure 2). Based on morphological characteristics, A. niger (35\%), A. ochraceus $(30 \%)$, and A. carbonarius (25\%) were common, while A. flavus and A. phoenicis were isolated only occasionally and in low numbers $(10 \%)$.

\section{Ochratoxigenic-producing abilities of isolates assayed}

Aspergillus isolates were verified for their capacity to produce OTA on YES medium. Detection of OTA in isolates studied was performed using a high-performance liquid chromatography method. Of 20 isolates, $12(60 \%)$ produced 0.36-1.27 $\mu \mathrm{g} / \mathrm{g}$ OTA. Most ochratoxigenic isolates were A. ochraceus (6), A. carbonarius (3), and A. niger (3). None of the A. phoenicis or A. flavus isolates were OTA producers. The percentage of ochratoxigenic isolates identified is also shown in Table 3. A. ochraceus was the main OTA producer, with $100 \%$ of the isolates able to produce this mycotoxin, followed by $A$. niger and A. carbonarius. 


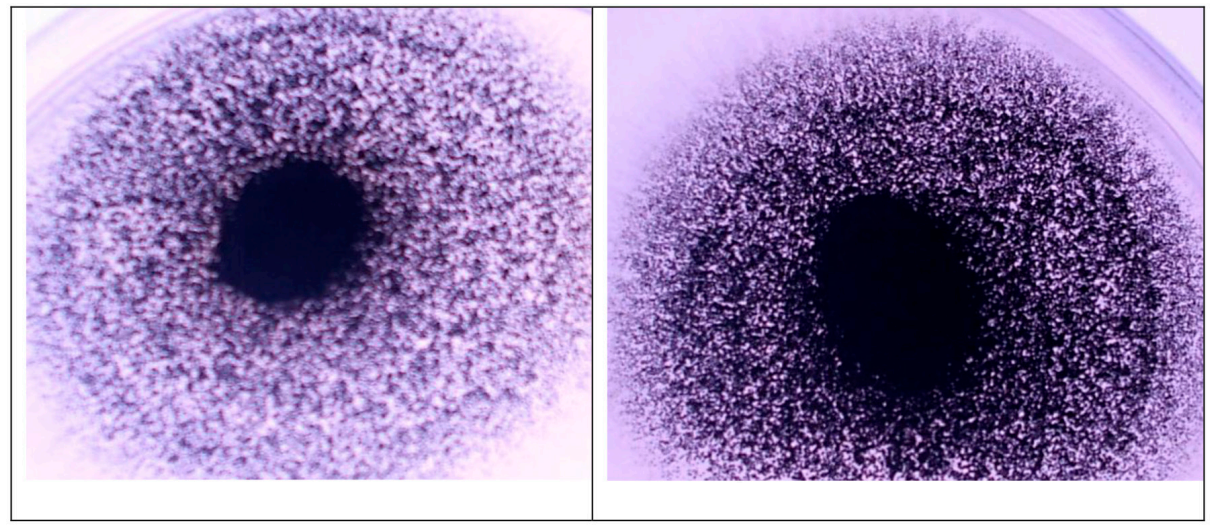

Figure 1. Aspergillus carbonarius (right) and A. niger (left) on malt extract agar 5 days after seeding.

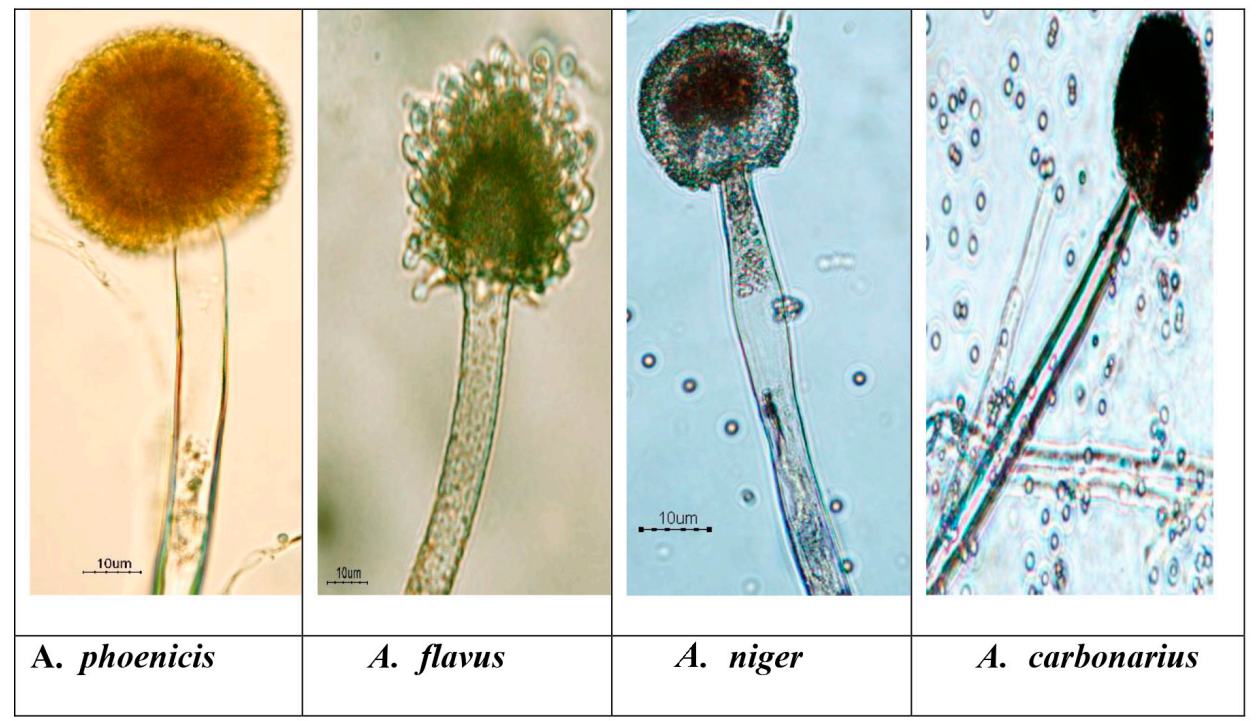

Figure 2. Microscopic characteristics of the 4 main Aspergillius species isolated on malt extract agar. Coenocytic, conidia, conidiospore, conidial heads, and the tiny black dots with condiospores are shown.

Table 3. Aspergillus strains isolated from peanuts in Saudi Arabia and the percentage of OTA-producing strains of each species.

\begin{tabular}{lcr}
\hline Aspergillius species & Number of isolated strains & Ochratoxigenic strains (\%) \\
\hline A. niger & 7 & 57 \\
A. ochraceus & 6 & 100 \\
A. carbonarius & 5 & 60 \\
A. phoenicis & 1 & 0 \\
A. flavus & 1 & 0 \\
Total aspergilli isolated & 20 & 65 \\
\hline
\end{tabular}




\section{Specificity of PCR and LAMP-PCR detection}

A single fragment of approximately $400 \mathrm{bp}$ was amplified by the OCRA1 and OCRA2 primers when genomic DNA from A. ochraceus isolates was used. No PCR product was observed with DNA from the Aspergillus isolates other than in A. ochraceus or in the case of other Aspergillius species (Figure 3). Amplification of specific gene segments was carried out at $65^{\circ} \mathrm{C}$ for $1 \mathrm{~h}$. Amplified LAMP products were analyzed by agarose gel electrophoresis and detected by staining gels with ethidium bromide. The 2 LAMP primer sets (AcPKS and AnPKS) showed positive reactions for the DNA of all A. carbonarius and A. niger isolates used in this study (Table 1). The amplification reaction produced ladder-like pattern bands on the agarose gels, with sizes ranging from $150 \mathrm{bp}$ up to the loading wells (Figure 4). The results showed that the LAMP assay was very specific for detecting and differentiating targeted species. Seven A. niger and 5 A. carbonarius isolates showed positive amplification by the LAMP assay using the AnPKS and AcPKS primers, respectively, while none of the primer sets amplified the DNA template of any closely related Aspergillius species, including A. phoenicis, A. flavus, and A. ochraceus, establishing the specificity of the LAMP test for $A$. carbonarius and A. niger (Figure 5).

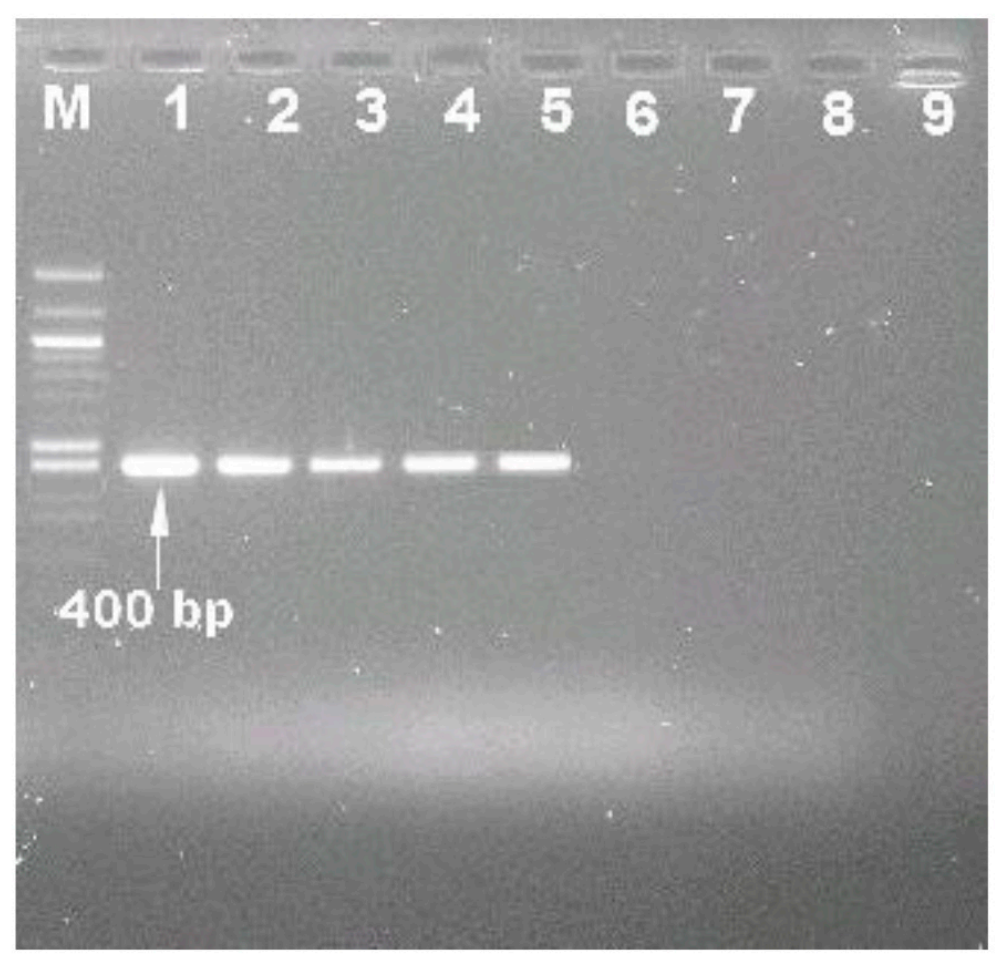

Figure 3. Electropherogram of PCR products revealed a specific band of $400 \mathrm{bp}$. Lanes $1-5=A$. ochraceus isolates; lane $6=$ A. flavus isolate; lane $7=A$. carbonarius; lane $8=A$. niger; lane $9=A$. phoenicis. Lane $M=100-b p$ DNA molecular weight marker. 


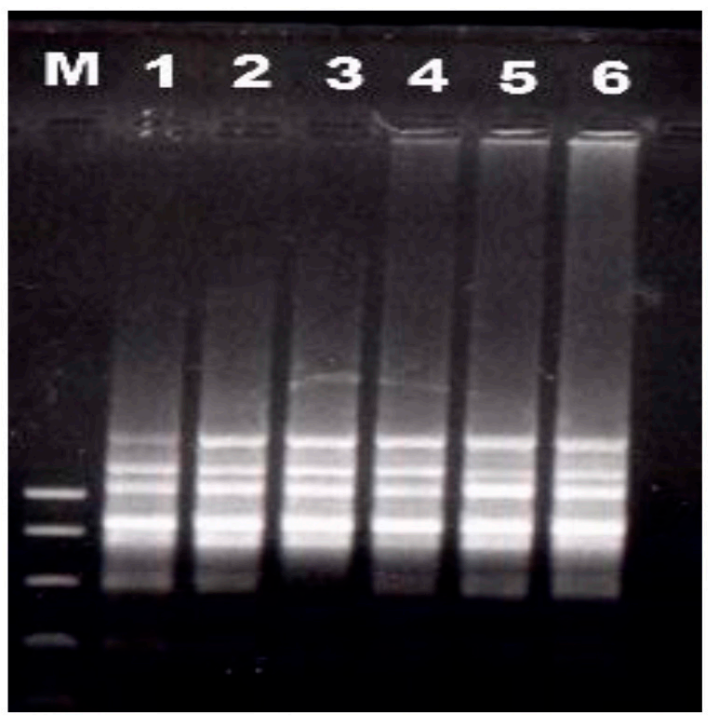

Figure 4. Comparison of template preparations for loop-mediated isothermal amplification (LAMP) reaction. Lanes 1-6 $=$ A. niger isolates. LAMP products were analyzed by $1.5 \%$ agarose gel electrophoresis. The amplification showed a nucleic acid ladder-like profile. Lane $M=100$-bp DNA molecular weight marker.
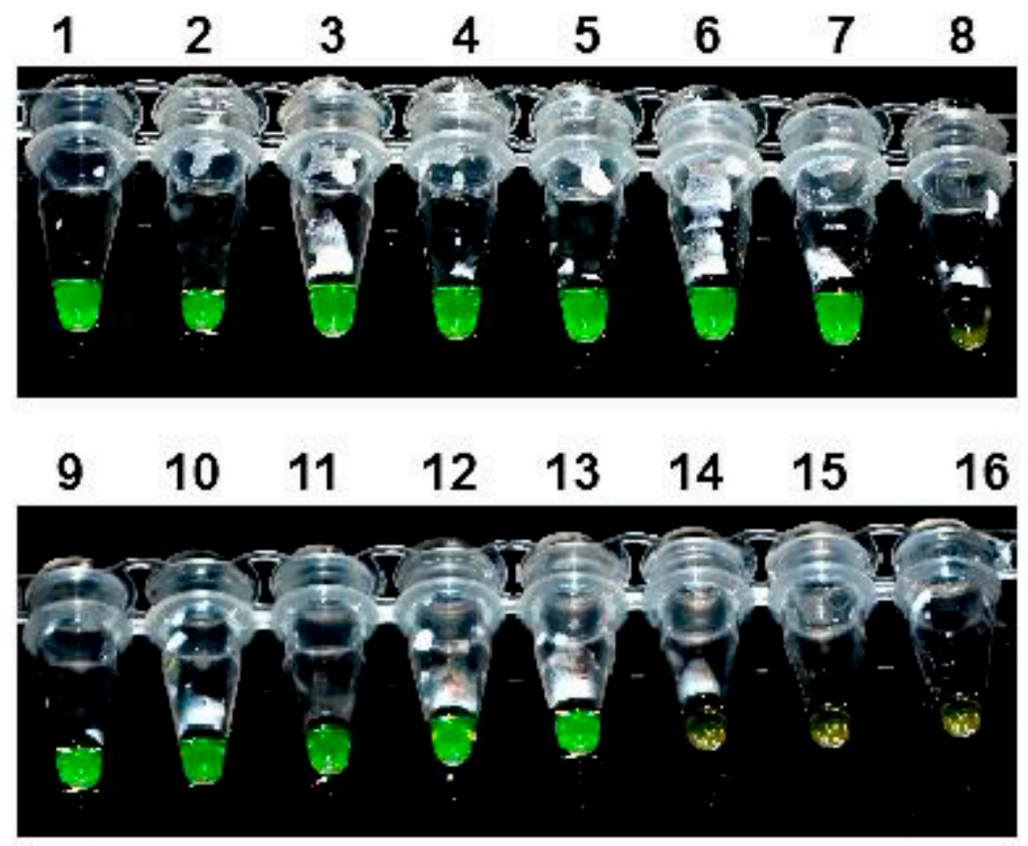

Figure 5. Specificity of LAMP-PCR assay, visual appearance of LAMP-PCR products using primer sets AnPKS and AcPKS, and naked-eye inspection under normal light. Lanes 1-7 = A. niger isolates; lane $8=A$. flavus isolate; lanes 9-13=A. carbonarius; lane $14=$ A. ochraceus; lane $15=$ A. phoenicis; lane $16=$ non-template DNA. 


\section{DISCUSSION}

The black aspergilla are the most common species associated with grapes, onions, maize, and peanuts, and also cause diseases on many grain crops such as peanut and maize seedling blight and maize kernel rot (Magnoli et al., 2006; Palencia et al., 2010). In the current study, statistical analyses revealed that the predominance of A. niger (35\%), A. ochraceus (30\%), and A. carbonarius (25\%) in disinfected peanut seeds. According to the previous mycobiota surveys, peanuts are frequently contaminated by section Flavi and this infection can occur during growth, harvesting, transportation, or storage (Barros et al., 2003; Passone et al., 2010).

The OTA content of the collected isolates was determined by high-performance liquid chromatography. In the present study, A. niger and A. carbonarius are two major producers of OTA. In harmony with Accensi et al. (2001), 25 to $100 \%$ of the isolates of $A$. carbonarius are ochratoxigenic, and 0.6 to $50 \%$ of the isolates of A. niger are ochratoxigenic. YES medium was chosen as it was previously evaluated as an optimal substrate for the evaluation of OTA production of black aspergilli (Spadaro et al., 2010). Other studies examined the production of OTA by Aspergillus species on other substrates, such as Czapek yeast extract agar. In a comparison of different Aspergillus isolates grown on YES or Czapek yeast extract, both culture media were found useful to evaluate OTA production (Bragulat et al., 2001).

A single fragment of approximately $400 \mathrm{bp}$ was amplified by the OCRA1 and OCRA2 primers when genomic DNA from A. ochraceus isolates was used. No PCR product was observed with DNA from the Aspergillus isolates other than A. ochraceus or for other genera. The primer pair OCRA1/OCRA2 was designed based on internal transcribed spacer sequence comparison of several strains of Aspergillus species (Patiño et al., 2005).

In the present study, LAMP reactions were conducted using the primer set previously designed by Storari et al. (2013) to identify and quantify 2 OTA-producing aspergilli collected from peanuts. Recently, LAMP-PCR assays were used in combination with a rapid protocol for isolating amplifiable DNA from the conidiospores of aflatoxin-producing $A$. nomius and A. flavus, respectively, in pure cultures and in naturally contaminated Brazil nuts (Luo et al., 2014). The LAMP assay is relatively equipment-free, only requiring a water bath or thermo block to maintain a constant temperature. It is therefore much less technically demanding compared to PCR. The present LAMP assay depends on the Bst-DNA polymerase, which is more stable than other DNA polymerases (Poon et al., 2006) such as Taq DNA polymerase, which is easily inhibited by biological substances. Detectable copies of DNA were obtained after only $1 \mathrm{~h}$ of incubation under isothermal incubation at $63^{\circ} \mathrm{C}$, and visual evaluation of the results could be carried out using a simple ultraviolet lamp.

\section{CONCLUSIONS}

Our results support the hypothesis that $A$. carbonarius and occasionally A. niger are the main producers of OTA in peanuts. The use of specific primers for the 2 LAMP primer sets (AcPKS and AnPKS) was efficient, fast, and reproducible in the detection A. carbonarius and $A$. niger. The 2 LAMP assays permitted the rapid and specific identification of DNA from OTA-producing black aspergilli, as well as isolates grown in pure culture. The techniques proposed in the current study are much faster and more reliable for detecting the presence of ochratoxigenic aspergilli found in peanuts. This method can be applied for agricultural quarantine pathogens. 


\section{ACKNOWLEDGMENTS}

Research supported by grant (project \#143001) from the Deanship of Scientific Research, King Faisal University (KFU). The financial support is gratefully acknowledged.

\section{REFERENCES}

Abarca ML, Accensi F, Cano J and Cabañes FJ (2004). Taxonomy and significance of black aspergilli. Antonie Van Leeuwenhoek 86: 33-49.

Abd-Elsalam KA, Bahkali AH, Moslem MA, Amin O, et al. (2011). An optimized protocol for DNA extraction from wheat seeds and loop-mediated isothermal amplification (LAMP) to detect Fusarium graminearum contamination of wheat grain. Int. J. Mol. Sci. 12: 3459-3472.

Accensi F, Abarca ML, Cano J, Figuera L, et al. (2001). Distribution of ochratoxin A producing strains in the A. niger aggregate. Antonie Van Leeuwenhoek 79: 365-370.

Ahmad MM, Abdin MZ and Javed S (2010). DNA based detection of Aspergillus using LAMP - a green technology for nucleic acid amplification. Int. J. Curr. Chem. 1: 18-22.

Almoammar H, Bahkali AH and Abd-Elsalam KA (2013). One-hour loop-mediated isothermal amplification assay for detection quarantinable toxigenic Fusarium garmanirum. Afr. J. Microbiol. Res. 7: 1179-1183.

Barros G, Torres A, Palacio G and Chulze S (2003). Aspergillus species from section Flavi isolated from soil at planting and harvest time in peanut-growing regions of Argentina. J. Sci. Food Agric. 83: 1303-1307.

Battilani P, Magan N and Logrieco A (2006). European research on ochratoxin A in grapes and wine. Int. J. Food Microbiol. 111: S2-S4.

Bahkali AH, Abd-Elsalam KA, Guo J-R, Khiyami MA, et al. (2012). Characterization of novel di-, tri-, and tetranucleotide microsatellite primers suitable for genotyping various plant pathogenic fungi with special emphasis on Fusaria and Mycospherella graminicola. Int. J. Mol. Sci. 13: 2951-2964.

Belli N, Marin S, Dauaigües A, Ramos AJ, et al. (2004). Ochratoxin A in wines, musts and garpe juices from Spain. $J$. Sci. Food Agric. 84: 591-594.

Bragulat MR, Abarca ML and Cabañes FJ (2001). An easy screening method for fungi producing ochratoxin A in pure culture. Int. J. Food Microbiol. 71: 139-144.

Dai TT, Lu CC, Lu J, Dong S, et al. (2012). Development of a loop-mediated isothermal amplification assay for detection of Phytophthora sojae. FEMS Microbiol. Lett. 334: 27-34.

Denschlag C, Vogel RF and Niessen L (2012). Hyd5 gene-based detection of the major gushing-inducing Fusarium spp in a loop mediated isothermal amplification (LAMP) assay. Int. J. Food Microbiol. 156: 189-196

Geiser DM, Klich MA, Frisvad JC, Peterson SW, et al. (2007). The current status of species recognition and identification in Aspergillus. Stud. Mycol. 59: 1-10.

Luo, J, Vogel RF and Niessen L (2012). Development and application of a loop-mediated isothermal amplification assay for rapid identification of aflatoxigenic molds and their detection in food samples. Int. J. Food Microbiol. 159: 214-224.

Luo J, Taniwaki MH, Iamanaka BT, Vogel RF, et al. (2014). Application of loop-mediated isothermal amplification assays for direct identification of pure cultures of Aspergillus flavus, A. nomius, and A. caelatus and for their rapid detection in shelled Brazil nuts. Int. J. Food Microbiol. 172: 5-12.

Magnoli C, Astoreca A, Ponsone L, Fernández-Juri MG, et al. (2006). Ochratoxin A and the occurrence of ochratoxin A-producing black aspergilla in stored peanut seed from Córdoba, Argentina. J. Sci. Food Agric. 86: 2369-2373.

Niessen L and Vogel R (2010). Detection of Fusarium graminearum DNA using a loop-mediated isothermal amplification (LAMP) assay. Int. J. Food Microbiol. 140: 183-191.

Niessen L, Gräfenhan T and Vogel RF (2012). ATP citrate lyase 1 (acl1) gene-based loop-mediated amplification assay for the detection of the Fusarium tricinctum species complex in pure cultures and in cereal samples. Int. J. Food Microbiol. 158: 171-185.

Notomi T, Okayama H, Masubuchi H, Yonekawa K, et al. (2000). Loop-mediated isothermal T., amplification of DNA. Nucl. Acids Res. 28: e63.

Palencia ER, Hinton DM and Bacon CW (2010). The black Aspergillus species of maize and peanuts and their potential for my cotoxin production. Toxins 2: 399-416.

Passone MA, Rosso LC, Ciancio A and Etcheverry M (2010). Detection and quantification of Aspergillus section Flavi spp. in stored peanuts by real-time PCR of nor-1 gene, and effects of storage conditions on aflatoxin production. Int. J. Food Microbiol. 138: 276-281. 
Patiño B, González-Salgado A, Gonzalez-Jaen MT and Vázquez C (2005). PCR detection assays for the ochratoxin producing Aspergillus carbonarius and Aspergillus ochraceus species. Int. J. Food Microbiol. 104: 207-214.

Perrone G, Susca A, Cozzi G, Ehrlich K, et al. (2007). Biodiversity of Aspergillus species in some important agricultural products. Stud. Mycol. 59: 53-66.

Pitt JI and Hocking AD (1997). Fungi and Food Spoilage. Vol. II. Blackie Academic and Professional, London.

Poon LL, Wong BW, Ma EH, Chan KH, et al. (2006). Sensitive and inexpensive molecular test for falciparum malaria: detecting Plasmodium falciparum DNA directly from heat treated blood by loop-mediated isothermal amplification. Clin. Chem. 52: 303-306.

Samson RA, Houbraken JAMP, Kuijpers AFA, Frank JM, et al. (2004). New ochratoxin A or sclerotium producing species in Aspergillus section Nigri. Stud. Mycol. 50: 45-61.

Sardiñas N, Vázquez C, Gil-Serna J, González-Jaén MT, et al. (2010). Specific detection of Aspergillus parasiticus in wheat flour by a highly sensitive PCR assay. Food Addit. Contam. 27: 853-858.

Selma MV, Martínez-Culebras PV and Aznar R (2008). Real-time PCR based procedures for detection and quantification of Aspergillus carbonarius in wine grapes. Int. J. Food Microbiol. 122: 126-134.

Spadaro D, Patharajan S, Lorè A, Gullino ML, et al. (2010). Effect of pH, water activity and temperature on the growth and level of ochratoxin A produced by three strains of Aspergillus carbonarius isolated from Italian vineyards. Phytopathol. Mediterr. 49: 65-73.

Storari M, von Rohr R, Pertot I, Gessler C, et al. (2013). Identification of ochratoxin A producing Aspergillus carbonarius and $A$. niger clade isolated from grapes usingthe loop-mediated isothermal amplification (LAMP) reaction. J. Appl. Microbiol. 114: 1193-1200.

Sun J, Najafzadeh MJ, Vicente V, Xi L, et al. (2010). Rapid detection of pathogenic fungi using loop-mediated isothermal amplification, exemplified by Fonsecaea agents of chromoblastomycosis. J. Microbiol. Methods 80: 19-24.

Téren J, Varga J, Hamari Z and Rinyu E (1996). Immunochemical detection of ochratoxin A in black Aspergillus strains. Mycopathologia 134: 171-176.

Tomlinson JA, Barker I and Boonham N (2007). Faster simpler, more-specific methods for improved molecular detection of Phytophthora ramorum in the field. Appl. Environ. Microbiol. 73: 4040-4047.

Varga J, Frisvad JC, Kocsube S, Brankovics B, et al. (2011). New and revisited species in Aspergillus section Nigri. Stud. Mycol. 69: 1-17. 